\title{
Student's Deductive Reasoning: Playing Detective Role In an Online Game
}

\author{
Hairus Saleh, Rahmania Sri Untari, Joko Susilo, Mu'alimin, Sirajuddin
}

\begin{abstract}
Students of the Elementary Teacher Training Department (PGSD) cannot distinguish deductive and inductive arrangements in a paragraph or a single story. As is known, in Indonesia, in conducting tests, there are several questions related to deductive reasoning. The response or perception of students after being a detective in online games for deductive reasoning also needs to be known. The data in this research were analyzed using the Kendall W. test method, which is included in the non-parametric statistical test to find a perception match. The research results show the $S$-result of 262 and $W$ results of 0.727. With $p 0.95$ and $n$ as many as 6 in the table of quantiles of kendall's test statistics, it can be seen that the value of s table is 7 . The provisions of h0 are rejected if $S$-count> S-table 262> 7, there is a perception match. Perception to be a detective for deductive reasoning is divided into 5 judgments, which are systematic approaches, general logic approaches that are devoted to radical logic approaches, and moderate logic approaches, and progress approaches.
\end{abstract}

Index Terms: deductive reasoning, game online, detective learning, CSI Hidden Crime

\section{INTRODUCTION}

Education fields include many kinds of thinking and reasoning abilities. Reasoning is the process of thinking that produces conclusions from perceptions, thoughts, or statements [1]. It is a mental activity by which we generate not available prior to the act of generation knowledge [2]. By definition, deductive reasoning produces valid conclusions, which must be true given that their premise is correct [1].

Deductive reasoning is the ability to reason a paragraph or event deductively or reasoning from a common event and the truth is known and ends in a conclusion or new knowledge that is of a special nature [3]. If there is no conclusion that meets the case or problem, a naive individual tends to respond with the phrase "There will be no continuation". Logically, this individual response is wrong because there are actually many valid conclusions that follow from each place.

PGSD students cannot distinguish between deductive and inductive patterns in a paragraph or a single story. As is known, in Indonesia, at the time of testing, there are several

Revised Manuscript Received on June 15, 2019

Hairus Saleh, Mathematic Education, Universitas Madura, Madura, Indonesia.

Rahmania Sri Untari, Information Technology Education, Universitas Muhammadiyah Sidoarjo, Sidoarjo, Indonesia.

Joko Susilo, Economics and Business Faculty, Universitas Muhammadiyah Sidoarjo, Sidoarjo, Indonesia.

Mu'alimin, Education and Teacher Training, IAIN Jember, Jember, Indonesia.

Sirajuddin, Education and Teacher Training, Universitas Muhammadiyah Makassar, Makassar, Indonesia. questions related to deductive reasoning. If the student cannot solve the problem of deductive reasoning there will be a shortage of points when working on the test either to work or to continue his studies. Knowledge plays the most specific role in the theory that reasoning is based on memories from previous conclusions [4], [5]. Although, according to this "case-based" theory of reasoning, human thought has nothing to do with logic. What happens is that one inference invokes another thought procedure that is useful in artificial intelligence [6]. When an activity has been repeated often enough, however, it begins to function like a content-specific rule [7]. Several solutions have been provided to overcome and enhance deductive reasoning, such as the book The Deductive Detective by Brian Rock, which invites elementary students to be detective and solve simple cases or problems at the elementary school level so that they are able to deduce general problems to be special. Playing a detective role can be the best solution for students to increase their sensitivity to deductive reasoning to handle a case or problem. Students can play detective games in an easy way, through a game application available on all types of mobile phones called CSI: Hidden. This convenience can make everyone or especially students become detectives to improve their deductive reasoning. Thus, it is also important to know how the response or perception of students after being a detective in an online game for deductive reasoning. This perception can make it easier for us to know the role of this online detective game for student deductive reasoning. In this research, this game has been used while mathematic learning within materi about get to know objects around within a simple addition that depicted in figure 3 . This game could used for increase deductive reasoning skill in mathematic learning about logic learning in sub-learning inductive reasoning and deductive reasoning. Also, this game was good to use for elementary students or higher students for to being the student that have a good deductive reasoning.

\section{METHOD}

\section{A. Research participants}

When using detective games in learning, 38 PGSD students or elementary school teacher candidates participated. To find out the perception, 6 students were chosen representing a total of 38 students who had used the game. 
The six students have characteristics so that they can be sampled, of which two students have high deductive reasoning, two students have moderate deductive reasoning, and two students have low deductive reasoning. This is known through the results of using CSI detective games. This value is reviewed from the number of stars obtained and the number of cases or problems that have been solved at the same time frame.

Table 1. Information and the condition of interviewees

\begin{tabular}{|c|c|c|}
\hline interviewee & $\begin{array}{l}\text { Student } \\
\text { condition }\end{array}$ & $\begin{array}{l}\text { Approach to } \\
\text { deductive } \\
\text { learning }\end{array}$ \\
\hline 1 & $\begin{array}{l}\text { High deductive } \\
\text { reasoning }\end{array}$ & Logic - progress \\
\hline 2 & $\begin{array}{l}\text { Moderate } \\
\text { deductive } \\
\text { reasoning }\end{array}$ & $\begin{array}{l}\text { Radical - } \\
\text { moderate }\end{array}$ \\
\hline 3 & $\begin{array}{l}\text { High deductive } \\
\text { reasoning }\end{array}$ & $\begin{array}{c}\text { Systematic - } \\
\text { logic }\end{array}$ \\
\hline 4 & $\begin{array}{l}\text { Low deductive } \\
\text { reasoning }\end{array}$ & $\begin{array}{l}\text { Moderate - } \\
\text { systematic }\end{array}$ \\
\hline 5 & $\begin{array}{l}\text { Moderate } \\
\text { deductive } \\
\text { reasoning }\end{array}$ & Moderate \\
\hline 6 & $\begin{array}{l}\text { Low deductive } \\
\text { reasoning }\end{array}$ & $\begin{array}{l}\text { Progrees - } \\
\text { radical }\end{array}$ \\
\hline
\end{tabular}

\section{B. Data collection}

The data source of this study is the use of CSI game data in the form of level scores, number of cases, and the number of stars obtained. In addition, there is a source of data in the form of semi-structured interviews of six students that last for 1-2 hours. The questions asked are related to their perceptions when they are detective in a digital game in developing deductive reasoning. Interviews are carried out without using a specific sequence (random order).

\section{Data Analysis}

This data was analyzed using the Kendall W test method. Kendall $w$ test is included in the non-parametric statistical test where to find a perceptual match of the three categories of assessors or more, they are students with high, medium, and low deductive reasoning who are known through the achieved scores in the game with five deductive reasoning approaches.

$$
\begin{aligned}
& W=\frac{s}{\frac{1}{12} k^{2}\left(N^{3}-N\right)} \\
& s=\sum\left(R j-\frac{2 R j}{N}\right)^{2}
\end{aligned}
$$

\section{RESULTS AND DISCUSSION}

\section{A. Becoming a detective in CSI Hidden Crime}

. Figure 1 shows the initial layout of the CSI game; Hidden Crime, which is an adventure puzzle game with the aim of uncovering the puzzle of evil with forensic skills.

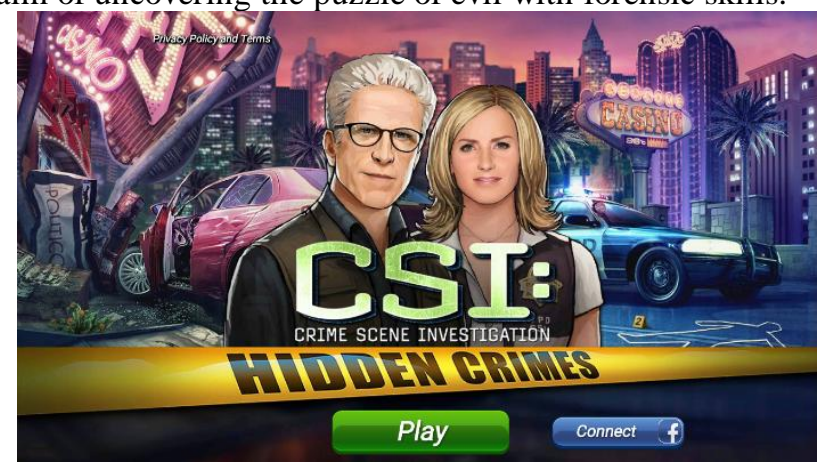

Figure 1. Front page layout of CSI:Hidden Crime

This Ubisoft game is played by puzzle game lovers to find hidden objects around the scene. Activities carried out in this game are finding various clues in a case, interrogating suspects and witnesses, and investigating further evidence through the mini games that have been provided.

The advantage of this game compared to others is because it can be played for free with certain conditions. The initial part of the mission requires full energy which is usually marked with a flash logo. One crime scene requires 15 energy to play, but sometimes there is a "discount" to 10 energy. But if you can collect all the stars, the energy drained is only 5 energies. Thus, the energy can be used in a series of problems or cases. Can use 15 minutes of energy charging time. Energy information can be seen in Figure 2.

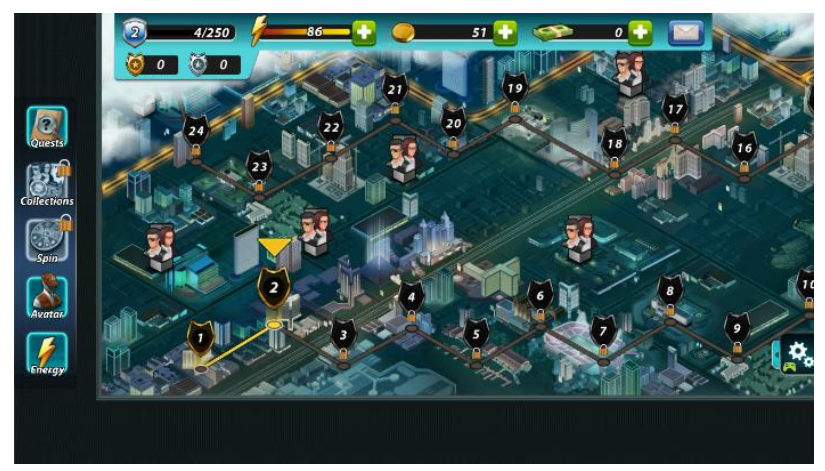

Figure 2. Map and detective account

This game is connected with other application features such as Facebook to store data on Ubisoft servers. Another advantage with Facebook connection is that it can work with fellow Facebook friends such as getting Golden Words or sending energy. If our deductive reasoning goes quickly it will provide benefits such as additional scores or even a star. 


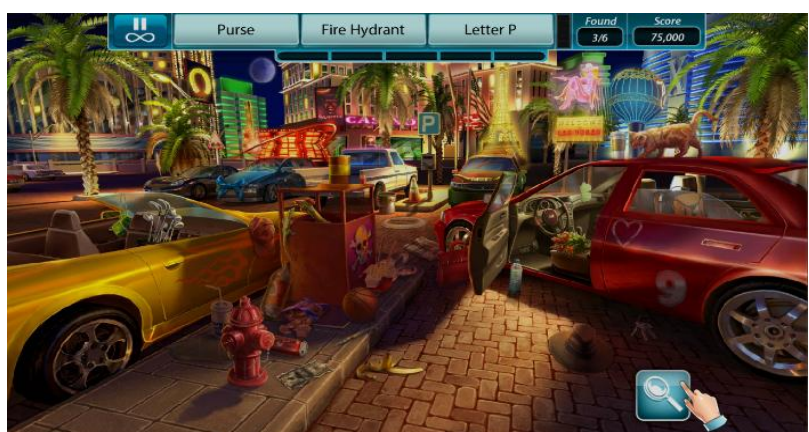

Figure 3. Crime-scene investigation

In addition, there are several helpful features to help speed up our deductive reasoning, such as touching with long time brackets on the name of the object being searched for or a magnifying glass called hints like in the lower right corner. Also i figure 3 , we can make students more understand about things in around.

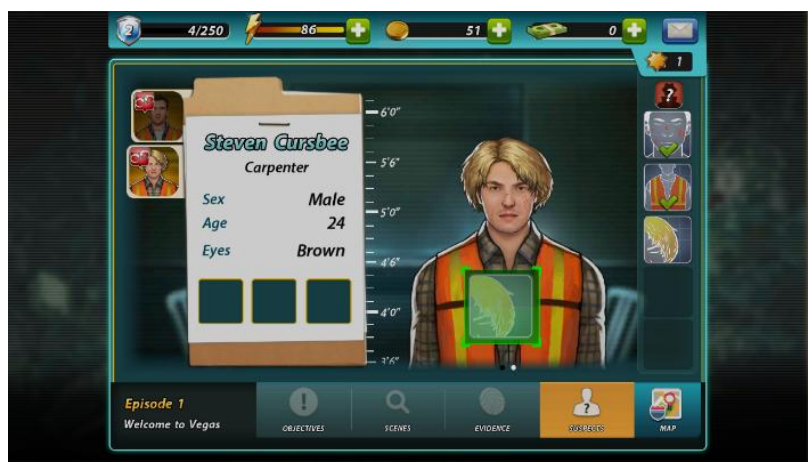

Figure 4. Final stage of deductive reasoning

In this game, if objects that are evidence in a case are found, there will be a clue about the perpetrator or suspect. Such as facial sketches, clothes worn or suspect hair color. The instructions make it easier for detectives to determine who is indeed a suspect in a case as shown in Figure 4.

\section{B. The Result of Kendall W test students perseption}

The results of the student assessment rankings are rearranged with a help table which aims to calculate the Kendall W. coefficients described in Table 2

Table 2. Scoring based on deductive approach

\begin{tabular}{|c|c|c|c|c|c|}
\hline \multirow{2}{*}{ Assessor } & \multicolumn{5}{|c|}{$\begin{array}{c}\text { Deductive Reasoning } \\
\text { Approach }\end{array}$} \\
\cline { 2 - 6 } & A & B & C & D & E \\
\hline 1 & 5 & 1 & 2 & 4 & 3 \\
2 & 3 & 2 & 1 & 5 & 4 \\
3 & 5 & 2 & 1 & 3 & 4 \\
4 & 4 & 1 & 3 & 5 & 2 \\
5 & 5 & 2 & 1 & 3 & 4 \\
6 & 4 & 2 & 1 & 5 & 3 \\
\hline Rj & 26 & 10 & 9 & 25 & 20 \\
\hline
\end{tabular}

By inputting the data into the Kendall $\mathrm{W}$ formula, this can be obtained tha the S-result is 262 and the W-result is 0.727 . With p 0.95 and $n$ as many as 6 on the Table quantity of kendall's test statistic, it can be seen that the value of S-table is 7. h0 is rejected h0 if s count $>\mathrm{s}$ Table 262> 7. With this statement, it can be concluded that there is a match of perceptions of students being detective in the game can improve student deductive reasoning.

\section{The Higher Student Perception of Being Detective for Deductive Reasoning}

Based on the results of the match through the control coefficient of the w test, a match was obtained from the 6 perceptual assessors so as to prove more deeply the results of interviews from the researcher to the 6 assessors. Perception of being a detective for deductive reasoning is divided into five judgments which include systematic approach, logic approach, in general which is devoted to the radical logic approach and moderate logic approach [8], and the process approach.

In addition, some students convey student perceptions about being a detective for deductive reasoning through transcripts of interviews. Interview data revealed several factors that contributed to students developing perceptions of more complex reasoning [14] [15] [16]. Evidence from each approach is presented below.

\section{a. THE SYSTEMATIC APPROACH}

In this detective game, doing work systematically is important for deductive reasoning. Systematic thinking can expand views and ideas so that they can answer questions or mysteries in the game, as well as perceptions from some of the following students

Deductive reasoning, I talk about being systematic in thinking, thinking and developing ideas in an organized way (interviewee no. 3)

I think deductive reasoning is, here, I find the word: to be systematic in thinking. In the game we have several problems that we need to solve; we think of something about the case instructions, he draws conclusions, which brings him to the next thing ... Logic is procedural, algorithmic, and logical thinking is the ability to construct these processes or to activate them in problem solving situations (interviewee no 4)

As explained through the results of the interview, systematically carrying out the instructions from this detective game can also generate systematic reasoning in thinking. The systemativeness allows a logic that underlies the existence of deductive reasoning.

\section{b. THE LOGIC APPROACH}

The logical approach arises because there is a systematic thought of deductive reasoning. The logic makes students who are detectives able to think logically so they can draw conclusions with the right things.

Logical thinking - I have no other definition - draw conclusions according to the rules of logic that are correct and do not cause new problems ... When a set of premises is given when being a detective, deductive reasoning leads to strong conclusions because of the logical structure (interviewee no 1)

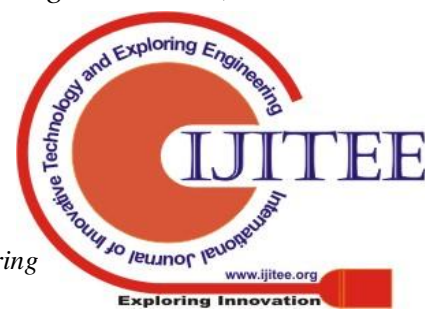


A detective who has good deductive reasoning understands how to examine logical relationships. See whether this evidence is related to the case or whether there is other evidence, and recall logical instructions to arrest the suspect (interviewee no. 3)

From the results of the interview, interviewees 1 perceived that being a detective in online games could develop deductive reasoning through his logical approach so that he could draw the conclusions of the right suspects. According to interviewee 3 , a logical approach can show the right deductive reasoning supported by evidence as a logic of reasoning.

\section{c. THE RADICAL LOGIC APPROACH}

One student with moderate deductive reasoning and one low deductive reasoning student said that deductive reasoning is not used in real life. They think radically that this case is only created because of the game, so we don't need to use that deductive reasoning that in the real world.

Let us say I am a mathematician, I will take theories that have been developed in the past because I did not want to bother finding a new premise. That's all radical logic. All new statements are obtained only by manipulation of propositions. This does not occur in everyday life where something cannot be derived logically from others (interviewee no. 2)

Deductive reasoning is not something that is meaningful to people by thinking by giving their conscience in it, thinking humanely, thinking openly. Being accurate is not something that matters to them because they live to be compassionate for them (interviewee no 6)

This radical thinking is not a negative perception nor a positive perception. Students think neutral about ways to develop their deductive reasoning. Students conclude that this is certainly through deductive reasoning because students have carried out activities to be detective so that they can deduce deductive reasoning..

\section{d. THE MODERATE LOGIC APPROACH}

Similar to the radical logic approach, this logical moderate approach in deductive reasoning does not require a logical mind that is good but can use common sense from thought. Besides, there are a number of things or events that do not require deductive reasoning.

I think logically that in life it is not always possible to use all these logical conclusions. Because, this is indeed a demand in being a detective in the game. Sometimes the situation is very complicated and there isn't always one thing that is deductively deducted from the others. In life sometimes there are exceptions where the situation is not in accordance with the rules. This means that it is impossible to apply deductive reasoning to those who are included in the exception (interviewee no. 2)
In non-mathematical situations, there are other factors that are more important than this validity. In fact, the goal changed. This is more a matter of how much your claim is convincing or can stand against other claims (interviewee no 4)

I say that we use logical rules in life. Indeed, when we become a detective we are not allowed to deliberately build this claim illogically. It's just clever how to draw conclusions so as not to be fooled. However, there are things in life that can have an impact on logical thinking. For example, sometimes people want to convince others about the truth of their arguments while the argument is illogical. (interviewee no. 5)

\section{e. THE PROGRESS APPROACH}

In the process approach in deductive reasoning, processes are the main thing in premise formation. A careful process can certainly help detectives in determining the premise of a case because it will be related to each other.

A person with good deductive reasoning can better and better solve problems or cases in life. For example, a teacher who plans learning and prepares learning materials, a doctor who learns many things about the disease and its handling, and also scholars who convey the message of the sentence. They all have to re-check the data that has been prepared, set learning or work strategies so they can achieve their goals. He is organized through processes and will then progress step by step towards solutions (interviewee no 1)

It's the same as systematic thinking, to develop dynamically. This is the use of logical and orderly process rules - walking step by step, going forward, organized in my thinking when I become a detective. (interviewee no. 6)

Interviewee 1 enjoys life as a detective by being meticulous in the identification process, which makes it easier for detectives to determine who the suspect is. Interviewee 6 said the same thing that the use of evidence with a logical and orderly process can run and organize students' thoughts when they play role as detective.

\section{Discussion}

From these differences, it can be seen that inductive does not require confidence in the truth of a conclusion because it has been explained at the beginning of a sentence or case.

From data analysis and interview results, it is shown that deductive reasoning is the ability to reason a thing to become an appropriate premise. There is research that shows that deductive reasoning is very sensitive from the type of deductive argument that is processed to be a number of different conclusions [9], as well as this study of differences in perception in terms of logic. 
This is not in accordance with the idea that deductive reasoning is a cognitive thinking process that is related to visuospatial or regular based processes [1].

When becoming a detective, strong arguments are needed so that the conclusions made will also be strong. The basic conclusion is part that deductive reasoning is a process that requires spatial observation and exploration [10]. The conclusions made by detectives are the result of a thorough observation of an exploration and spatial space. There are two differences of opinion in this research about being a detective in deductive reasoning, one of that is deductive thinking and free thinking in daily life need a deductive reasoning and two of that deductive thinking and free thinking in daily life didnt need deductive reasoning. From the difference between the two different opinions related to deductive reasoning, namely determining how evaluative feedback improves performance and no feedback during the performance [11]. It is realized that there will be a lack of theoretical theory that supports being a detective in online games for the development of deductive reasoning. From these shortcomings, it is expected that from the results of this study it can be an inspiration that online games can improve thinking skills and reasoning abilities of students and students. The same as using technology-based learning media media can improve some abilities of school students and university students [12] - [ 14] so that it has a good impact on education in Indonesia in the 21 st century.

\section{CONCLUCIONS}

Playing role as a detective can be the best solution for students to increase their sensitivity to deductive reasoning to handle a case or problem. The results showed that the s-result was 262 and the W-result was 0.727 , with p 0.95 and $n$ as many as six in Table Quantum of Kendall's test statistic. s-table. 262> 7 then $\mathrm{h}_{0}$ is rejected. With this statement, it can be concluded that there is a compatibility of perceptions of students being detective in a game that can improve students' deductive reasoning. Perception of being a detective for deductive reasoning is divided into five judgments, namely systematic approach, general logic approach that is devoted to a radical logic approach and moderate logic approach and process approach.

\section{ACKNOWLEDGMENT}

We would like to thank Muhammadiyah Sidoarjo University, Madura University, and IAIN Jember for the great opportunity given to conduct this Cross-University research.

\section{REFERENCES}

1. P. N. Johnson-Laird, "DEDUCTIVE REASONING," Annu. Rev. Psychol, vol. 50, pp. 109-135, 1999.

2. W. Bibel and C. Kreitz, "Deductive Reasoning Systems," International Encyclopedia of the Social \& Behavioral Sciences, vol. 5. Oxford: Elsevier, pp. 933-940, 2018.

3. J. Schechter, "Deductive Reasoning," no. i.

4. C. K. Riesbeck and R. C. Schank, Inside Case Based Reasoning. Hillsdale: Erlbaum, 1989.

5. J. Kolodner, Case-Based Reasoning. San Moteo: CA, 1993.

6. B. Smyth and M. T. Keane, "Remembering to forget: a competence-preserving deletion policy for CBR systems," in 14th Int. Jt.
Conf. Artificial Intelligence, 1995

7. S. A. Eisenstadt and H. A. Simon, "Logic and thought," Minds Mach, vol. 7, p. 365--385, 1997.

8. M. Ayalon and R. Even, "Deductive reasoning: in the eye of the beholder," Educ. Stud. Math., vol. 69, pp. 235-247, 2008.

9. J. Prado, A. Chadha, and J. R. Booth, "The Brain Network for Deductive Reasoning : A Quantitative Meta-analysis of 28 Neuroimaging Studies," J. Cogn. Neurosci., vol. 23, no. 11, pp. 3483-3497, 2011.

10. V. Goel, "Cognitive Neuroscience of Deductive Reasoning," 2003.

11. S. Khemlani and A. Moore, "Evaluative feedback can improve deductive reasoning Experiment 1 : Sentential reasoning," 2009.

12. M. F. Amir, C. Chotimah, R. Afandi, H. E. Rudyanto, and I. Anshori, "Design Research Study : Investigation of Increasing Elementary Student 's Spatial Ability Using 3Dmetric," J. Adv. Res. Dyn. Control Syst., vol 10, no. 6, pp. 1707-1713, 2018.

13. M. F. Amir, N. Fediyanto, C. Chotimah, and H. E. Rudiyanto, "Developing 3Dmetric Media Prototype through a Hypothetical Learning Trajector to Train Students Spatial Skill," J. Adv. Res. Dyn. Control Syst., vol. 10, no. 02-Special Issue, pp. 1537-1542, 2018.

14. M. F. Amir, F. N. Hasanah, and H. Musthofa, "Interactive Multimedia Based Mathematics Problem Solving to Develop Student s ' Reasoning," Int. J. Eng. Technol., vol. 7, no. 2.14, pp. 272-276, 2018.

\section{AUTHORS PROFILE}

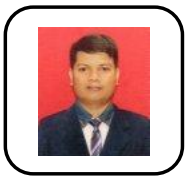

Hairus Saleh is a lecturer in the mathematics education department at Universitas Madura from 2014 until now. He is now pursuing a doctoral degree in mathematics education at Malang state university, Indonesia. Topics that are often used as research are about mathematics education in various fields, such as mathematics in learning media in technology and problem solving in mathematic

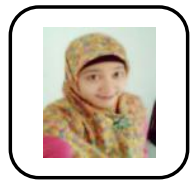

Rahmania Sri Untari was born in Malang, April 19, 1989 Undergraduate education was completed in the Informatics Engineering Education Study Program, State University of Malang in 2011. S2 education in the Vocational Education Postgraduate Program was completed in 2015. In 2016, the author continued S3 Education Department of Vocational Education at the State University of Malang and is still in the study period. In 2011 the author began his career at SMA Negeri 6 Surabaya as an Informatics Engineering teacher and became a vice principal part of the curriculum. Furthermore, in 2015 the author continued his career to become a permanent Lecturer in Information Technology Education Study Program at Muhammadiyah University of Sidoarjo. Both authors' parents are teachers, which is what makes the writer interested in becoming an educator. Because actually being a teacher is a call, and a professional teacher is the best teacher in the eyes of children.

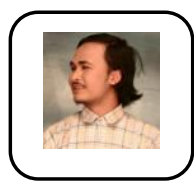

Joko Susilo is an Associate Lecturer form Universitas Muhammadiyah Sidoarjo, His research interests include learning technology media and art of children.

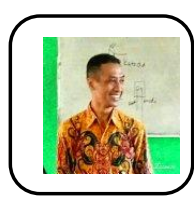

Mu'alimin was born in Lamongan, February 4, 1975 Undergraduate education was completed in the education of islamic religion Study Program, STAIN Malang in 1998. S2 education in the islamic religion Postgraduate Program at University of Muhammadiyah Sidoarjo was completed in 2007. In 2008, the author continued S3 Islamic Education Managament at Maliki State Islamic University the of Malang was completed In 2018. The author began his career at supervisor of education (Madrasah) Pasuruan. Furthermore, in 2018 the author continued his career to become a permanent Lecturer in Faculty of Education and Teacher Training IAIN Jember.

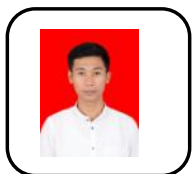

Sirajuddin is a lecturer in the education department of elementary school teachers at Universitas Muhammadiyah Makassar. He is now pursuing a doctoral degree in education mathematics at Universitas Negeri Malang, Indonesia. Research topics are often used are mathematics education especially in elementary school, learning technology media, and game technology. Published By:
Blue Eyes Intelligence Engineering
\& Sciences Publication 